\title{
Unilateral Breast Carcinoma
}

National Cancer Institute

\section{Source}

National Cancer Institute. Unilateral Breast Carcinoma. NCI Thesaurus. Code C46073.

Breast carcinoma of one breast, or one side of the breast. 